Kimberly R. Boer

Oddeke van Ruler

Arnold A. P. van Emmerik

Mirjam A. Sprangers

Sophia E. de Rooij

Margreeth B. Vroom

Corianne A. J. M. de Borgie

Marja A. Boermeester

Johannes B. Reitsma

The Dutch Peritonitis Study Group

\section{Factors associated with posttraumatic stress symptoms in a prospective cohort of patients after abdominal sepsis: a nomogram}

Received: 14 May 2007

Accepted: 17 October 2007

Published online: 16 January 2008

(C) The Author(s) 2008

Electronic supplementary material The online version of this article (doi:10.1007/s00134-007-0941-3) contains supplementary material, which is available to authorized users.

Authors' contributions: M. A. B., K. R. B., C. A. J. M. dB. and M. A. S. designed the study and advised on PTSD and depression. All information pertaining to surgical procedures and ICU stay for the final manuscript were considered by M. A. B. and S. E. dR. K. R. B. and O. vR. were responsible for the coordination of the study, including contacting patients, collecting data and entering data. K. R. B., J. B. R. and M. A. B. analyzed data, and K. R. B. was responsible for the final manuscript. K. R. B., O. vR.,

C. A. J. M. dB., J. B. R., M. A. S., S. E. dR., A. A. P. vE. and M. A. B. interpreted and discussed all data. All authors read and approved the final manuscript.

Competing interests: There are no competing interests for any of the authors for the content of this paper.

The RELAP trial clinical centers and the investigators of the Dutch Peritonitis Study Group are listed in the Appendix.

Financial support: Supported by the Dutch Organization for Health Research and Development (ZonMW), The Hague, The Netherlands. Health Care Efficiency Program, grant number 945-02-028.
K. R. Boer · C. A. J. M. de Borgie •

J. B. Reitsma (『)

University of Amsterdam, Department of Clinical Epidemiology, Biostatistics and Bioinformatics, Academic Medical Center,

1100 DE, PO Box 22700, Amsterdam, The Netherlands

e-mail: j.reitsma@amc.nl

O. van Ruler · M. A. Boermeester University of Amsterdam, Department of Surgery, Academic Medical Center, Amsterdam, The Netherlands

A. A. P. van Emmerik

University of Leiden, Department

of Psychology,

Leiden, The Netherlands

M. A. Sprangers

University of Amsterdam, Department of Medical Psychology, Academic Medical Center,

Amsterdam, The Netherlands

S. E. de Rooij

University of Amsterdam, Department of Internal Medicine, Geriatrics, Academic Medical Center,

Amsterdam, The Netherlands

\section{B. Vroom}

University of Amsterdam, Department of Intensive Care Medicine, Academic Medical Center.

Amsterdam, The Netherlands
The Dutch Peritonitis Study Group University of Amsterdam, Department of Surgery, Academic Medical Center, 1100 DE, PO Box 22700, Amsterdam, The Netherlands
Abstract Objective: To determine to what extent patients who have survived abdominal sepsis suffer from symptoms of posttraumatic stress disorder (PTSD) and depression, and to identify potential risk factors for PTSD symptoms. Design and setting: PTSD and depression symp- toms were measured using the Impact of Events Scale-Revised (IES-R), the Post-Traumatic Symptom Scale 10 (PTSS-10) and the Beck Depression Inventory II (BDI-II). Patients and participants: A total of 135 peri- tonitis patients were eligible for this study, of whom 107 (80\%) patients completed the questionnaire. The me- dian APACHE-II score was 14 (range 12-16), and $89 \%$ were admitted to the ICU. Measurements and results: The proportion of patients with "moder- ate" PTSD symptom scores was $28 \%$ (95\% CI 20-37), whilst 10\% (95\% CI 6-17) of patients had "high" PTSD symptom scores. Only 5\% (95\% CI 2-12) of the patients expressed severe depression symptoms. Factors 
associated with increased PTSD symptoms in a multivariate ordinal regression model were younger age ( 0.74 per 10 years older, $p=0.082)$, length of ICU stay (OR $=1.4$ per doubling of duration, $p=0.003$ ) and having some $(\mathrm{OR}=4.9, p=0.06)$ or many $(\mathrm{OR}=55.5, p<0.001)$ traumatic memories of the ICU or hospital stay. Conclusion: As many as $38 \%$ of patients after abdominal sepsis report elevated levels of PTSD symptoms on at least one of the questionnaires. Our nomogram may assist in identifying patients at increased risk for developing symptoms of PTSD.

Keywords Peritonitis - Sepsis . Posttraumatic stress disorder - PTSD . Depression - Intensive care - IES-R · PTSS-10 · BDI-II
Abbreviations APACHE-II: Acute Physiology and Chronic Health Evaluation II - ARDS: Acute respiratory distress syndrome . APS: Acute Physiology Score . DSM-IV: Diagnostic and Statistical Manual of Mental Disorders-Fourth

Edition - ICU: Intensive care unit . $I Q R$ : Interquartile range .

IES-R: Impact of Events-Revised Questionnaire $\cdot N$ : Number of patients - n. a.: Not applicable . OR: Odds ratio - PTSD: Posttraumatic stress disorder . PTSS-10: Post-Traumatic Stress Syndrome 10-Questions Inventory • SCID: Standardized Clinical Interview Diagnosis $\cdot S D$ : Standard deviation $\cdot 95 \%$ CI: $95 \%$ Confidence intervals

\section{Introduction}

Posttraumatic stress disorder (PTSD) is the development of psychological and physical symptoms following exposure to one or more traumatic events [1,2]. PTSD symptoms include intrusive recollections (re-experiencing the trauma in flashbacks, memories or nightmares); avoidant and numbing symptoms (including diminished emotions and avoidance of situations that are reminders of the traumatic event); and hyperarousal (including increased irritability, exaggerated startle reactions or difficulty sleeping or concentrating) [3]. PTSD symptoms have a major impact on life, illustrated by the fact that the patients have a reduced quality of life [4] and frequently suffer from depression [5].

Events that typically trigger the development of PTSD include exposure to violent events such as rape, domestic violence, child abuse, war, accidents, natural disasters and political torture, all of which include a threat to life [6-8]. Increasingly PTSD has also been found in patients who have survived a major, life-threatening disease and patients who have spent a significant amount of time in an intensive care unit (ICU) [9-13]. Severe peritonitis (or abdominal sepsis) is such a disease where typically an episode of acute and severe illness $[14,15]$ is followed by a lengthy ICU stay and a long recovery period that often includes multiple surgical and non-surgical interventions [16-22]. This combination of factors could make this patient group particularly vulnerable for developing PTSD symptoms. To date, little is known about the presence and severity of PTSD and possible risk factors in patients recovering from severe peritonitis [15].

Therefore, our aims were to determine the presence and level of symptoms of PTSD in patients surviving abdominal sepsis. In addition, we searched for demographic and disease-related factors associated with higher levels of PTSD symptoms. Identification of such factors may be important to determine possible targets of intervention and to select patients for psychological assessment interviews.

\section{Methods}

\section{Study design}

Our study was embedded in an ongoing randomized clinical trial (the RELAP Trial) evaluating two surgical treatment strategies for patients with secondary peritonitis after the initial emergency laparotomy. Patients were enrolled between December 2001 and February 2005 in two academic medical centers and seven regional teaching hospitals in The Netherlands. All patients were followed up for 12 months after initial (index) laparotomy.

The study was approved by the medical ethics committee of the Academic Medical Center, Amsterdam. All patients gave informed consent to participate in this study.

\section{Study population}

Patients were eligible for the RELAP trial if they had a clinical diagnosis of secondary peritonitis requiring emergency laparotomy and an Acute Physiology and Chronic Health Evaluation II (APACHE-II) score above 10. Further details of the study population can be found elsewhere [23].

\section{Data collection}

All self-administered PTSD questionnaires were distributed by mail to patients who survived at least 12 months following initial emergency laparotomy, with a reminder by phone within 2 weeks in the case of no response. After 
1 month without response a new questionnaire including a reminder letter was sent.

Instruments assessing the level of PTSD symptoms

We used two instruments with good psychometric characteristics $[24,25]$ for measuring PTSD symptoms in research settings: the Post-Traumatic Stress Scale 10 [26] and the Impact of Event Scale-Revised [27, 28].

The Post-Traumatic Stress Syndrome Scale 10 (PTSS10) was originally designed to diagnose PTSD according to the Diagnostic and Statistical Manual of Mental Disorders III (DSM-III) criteria in victims of natural disasters [14]. The PTSS-10 is now a widely used self-report questionnaire assessing symptoms related to PTSD, particularly in critically ill and ICU patients $[4,11,12]$. The PTSS-10 consists of 10 items, each of which ranges from 1 point (none) to 7 points (always). The total score ranges from 10 to 70, with higher scores indicating more symptoms; scores of 35 or above are considered indicative of PTSD [11, 29].

The Impact of Events Scale-Revised (IES-R) is one of the most commonly used self-report questionnaires for determining PTSD symptomatology following a trauma [27]. The IES-R consists of 22 items, each ranging from 0 (no problems) to 4 (frequent problems), with the total score ranging from 0 to 66 . Scores above 24 points are generally considered indicative of PTSD, with higher scores indicating more symptoms [28]. The IES-R has been developed based on DSM-IV criteria and therefore has three distinct subscales, the avoidance subscale (eight questions), the intrusion subscale (eight questions) and the hyperarousal subscale (six questions) [28,30], and is one of the most frequently used self-report questionnaires in both the clinic and in PTSD research [27].

\section{Potential risk factors}

Potential risk factors were selected from previous studies [31] examining factors for increased mortality and morbidity [17-22, 32, 33] in secondary peritonitis supplemented with specific factors mentioned in the PTSD literature $[6,9-11,14,34,35]$. We divided these factors into three distinct categories.

General patient characteristics included age, gender and the presence of major comorbidity (cardiovascular disease; COPD; renal failure; diabetes; malignancy).

Disease characteristics and postoperative course included severity of disease measured at the time of initial laparotomy using the APACHE-II score. As several components of the APACHE-II score are already considered in a univariate analysis (namely age and comorbidity); we chose to replace the APACHE-II score with the APS score as a potential predictor of PTSD [36]. The APS comprises only the acute components of the APACHE-II score, without age and comorbidity. Postoperative characteristics included administration of hydrocortisone during ICU stay [13, 37], development of acute respiratory distress syndrome (ARDS), [4, 12, 20], number of relaparotomies, duration of ICU and hospital stay, the development of a disease-related major morbidity during 6 months' follow-up [23] and an enterostomy present after 6 months' follow-up.

Traumatic memories of ICU/hospital stay were assessed using the four-item adverse experiences questionnaire, which captures four types of traumatic memories of the stay in the ICU or hospital ward: nightmares, fear and panic, pain, and difficulty in breathing [13]. Patients scored the frequency of traumatic memories of their stay in the ICU or hospital ward using a four-point scale of 0 (never), 1 (sometimes), 2 (regularly) or 3 (often), administered concurrently with the PTSS-10 and IES-R questionnaires after at least 12 months' follow-up. These were subsequently summed and classified into three graded categories of traumatic memories: 0 (no traumatic memories), 1-4 (some traumatic memories), more than 4 (many traumatic memories).

We also collected data on whether patients had experienced other traumas or whether a close family member or friend had experienced a trauma within the previous 3 years. We used questions 29 and 30 from the Life Stressor Checklist-Revised [38], administered at the same time as the PTSS-10, IES-R and Beck Depression Inventory II (BDI-II) questionnaires. Responses were given dichotomously as yes or no, and patients were subsequently asked to specify the event type [38]. These questions were asked to determine to what extent the PTSD symptomatology found in this patient group was due to their peritonitis or to other traumatic events.

\section{Data analysis}

We used two instruments aimed at measuring the presence and severity of PTSD symptoms in our population, each with their own cut-off value. Combining data from two instruments measuring the same construct (PTSD symptoms) may lead to a more robust classification of patients. To preserve the natural ordering of patients who scored below the cut-off value on both questionnaires ('low-scoring patients'), patients scoring above the cut-off on only one of these questionnaires ('moderate scoring patients') and patients scoring above the cut-off on both questionnaires ('high-scoring patients'), we applied ordinal regression modeling. The proportion of patients in each of these three categories is presented with $95 \%$ confidence intervals (95\% CI) using the method of Wilson [39].

Potential predictors for PTSD symptoms were analyzed using an ordinal logistic regression model. This ordinal regression model is an extension of the binary 
logistic model and is appropriate when a continuous trait is grouped into several categories by using cut-offs [40].

All potential predictors for PTSD symptoms were first examined in univariate ordinal regression models. Factors with a $p$-value of less than 0.1 were entered in a multivariate ordinal logistic regression model. If variables within a group of predictors were strongly correlated, only the factor with the strongest univariate relationship and/or most relevant clinical interpretation was added to the model. Because the literature on PTSD and ICU studies shows them to be clinically relevant, age and gender were always included in the multivariate model regardless of the strength of their associations [34].

In addition, a factor comprised of other non-related traumas that the patient had experienced within the previous 3 years was included in the final model to assess its potential confounding role.

The fit and validity of the model was evaluated by checking the discriminatory properties (overlap in risk scores of patients with different outcomes), the proportional odds assumption (test for parallel lines) and calibration (closeness in expected and observed numbers of patients evaluated by an extension of the Hosmer-Lemeshow goodness-of-fit statistic).

Calibration was checked by comparing expected and observed number of patients in each of the three outcome categories across deciles of expected risk and tested for significance by using an extension of the HosmerLemeshow goodness-of-fit statistic [41].

Nomogram: A nomogram was developed to visualize the prognostic strength of the different factors from the multivariate model in a single diagram. A nomogram allows readers to calculate an expected distribution of PTSD symptomatology ('low-scoring', 'moderate-scoring' and 'high-scoring' patients) based on a specific profile of a patient. The number of points for each predictor was based on the original coefficient from the multivariate ordinal model. The total number of points derived by specifying values for all predictors was used to calculate the expected probabilities that a patient would be a 'low-scoring patient', a 'moderate-scoring patient' or a 'high-scoring patient'.

Analyses were performed using SAS software version 9.1 (SAS Institute Inc., Cary, NC, USA).

\section{Results}

Of the total of 132 patients eligible for this study, 108 $(80 \%)$ patients responded to the questionnaire (Fig. 1).

On average the responses were provided approximately 12.5 months following initial emergency laparotomy. There were no significant differences in any of the
Fig. 1 Flowchart summarizing inclusion and response

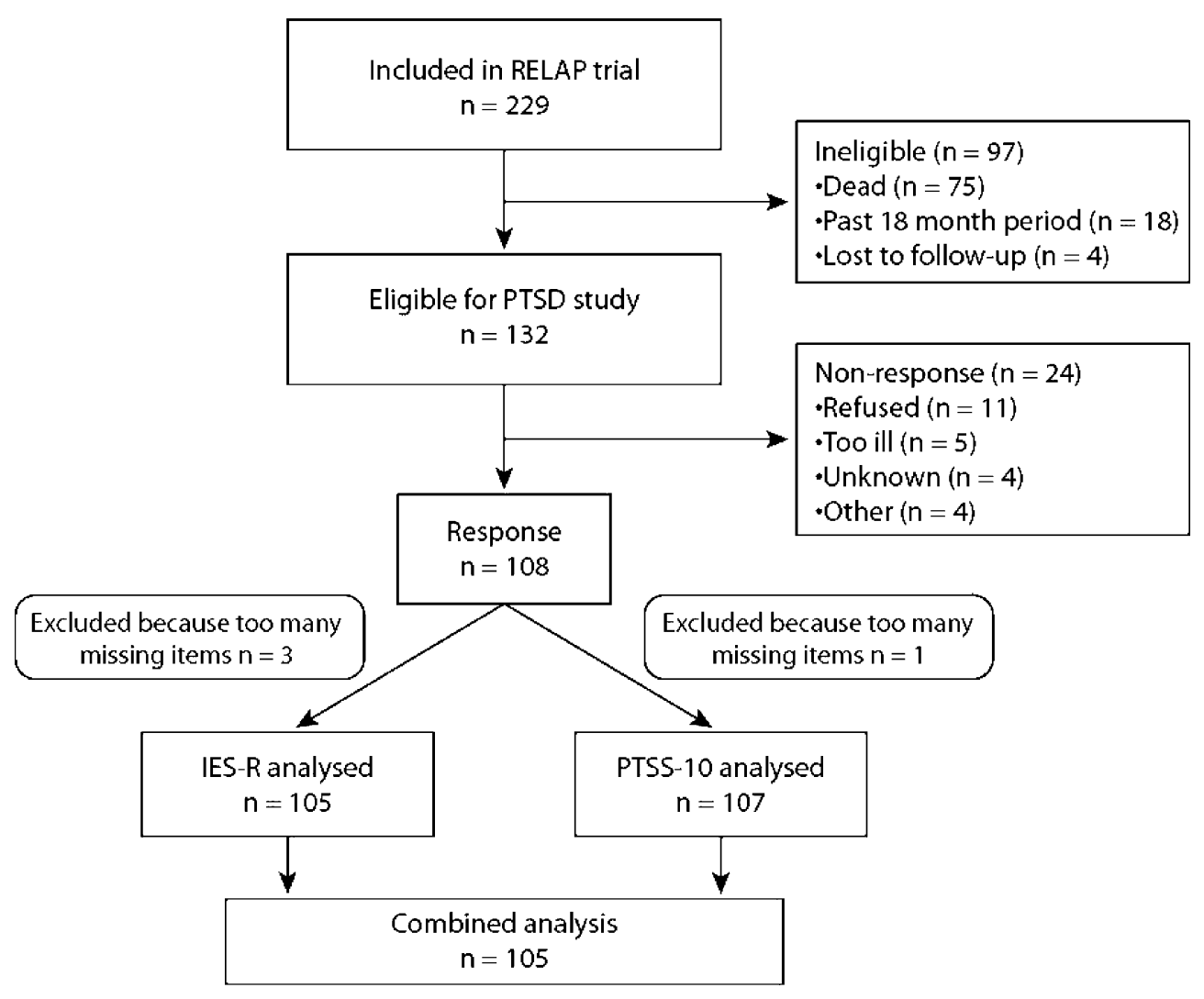


patient or disease characteristics between respondents and non-respondents.

The median age of patients was 66.8 years and $54 \%$ were male. Patients were severely ill, with a median APACHE-II score of 14 and a median APS score of 6 , and $5 \%$ had a major comorbidity (Table 1). Ninety-six patients (89\%) were admitted to ICU: their median ICU-stay was 7 days, and these patients were mechanically ventilated for a median of 5 days. Patients were hospitalized for a median period of 28 days (IQR 19-55 days). Fifty-one percent of patients also underwent another trauma in the 3 years prior to filling in the PTSD questionnaires.

\section{Prevalence of PTSD symptoms}

The proportion of 'moderate-scoring' PTSD patients was $28 \%$ (95\% CI 20-37\%), whilst 10\% (95\% CI 6-17\%) of patients were 'high-scoring' patients (Table 1). Detailed information on depression and PTSD symptoms is presented in the electronic supplementary material (ESM).

Table 1 Association between severity of PTSD symptoms (three categories) and patient, disease operative and postoperative characteristics: results from univariate ordinal regression models

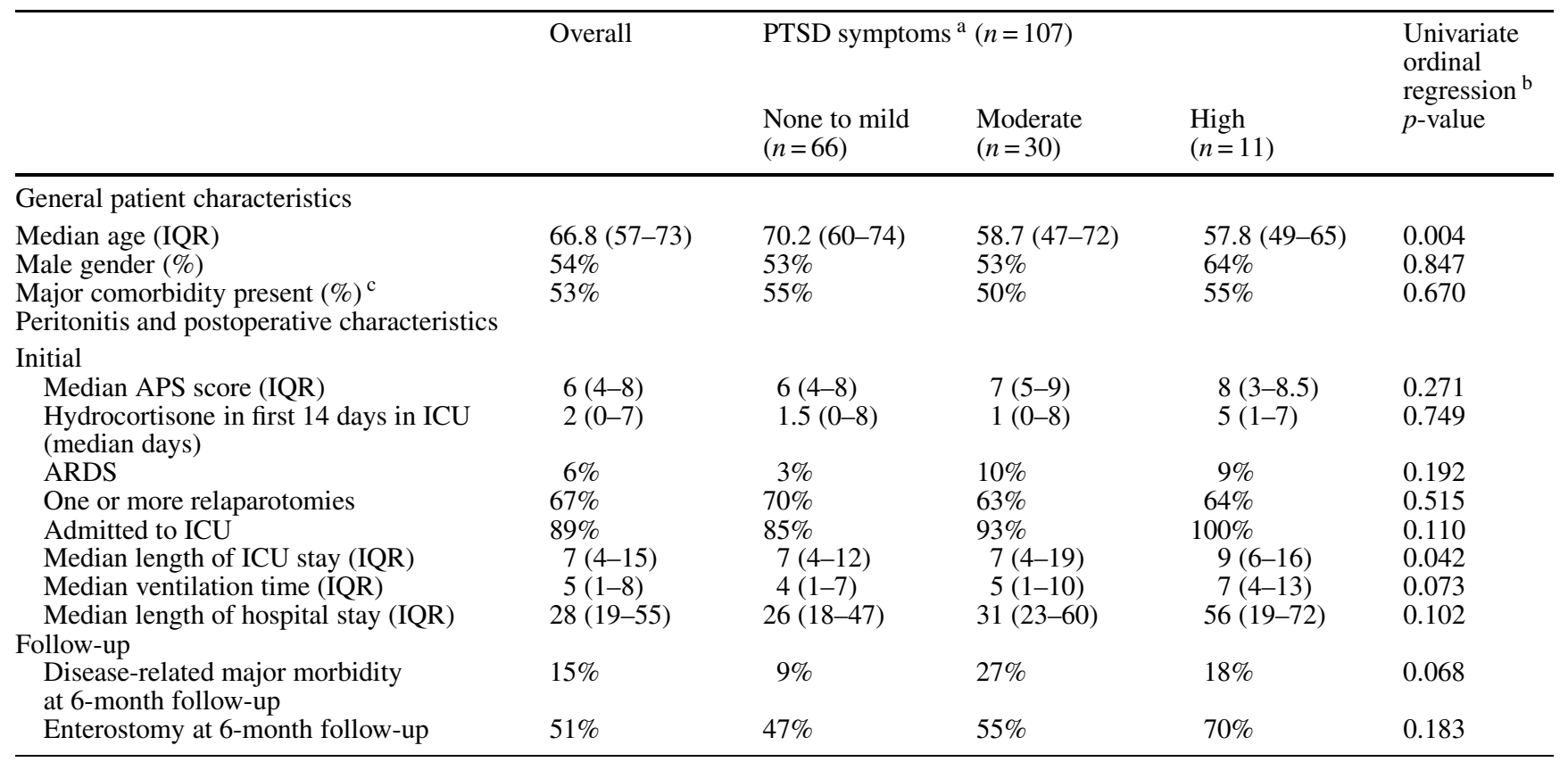

$I Q R$, Interquartile range; a Three graded outcomes: none to mild, moderate and high; two patients' data are based on only one completed questionnaire; ${ }^{b}$ All models were checked for parallel lines to see if an ordinal test for significance was appropriate; ${ }^{\mathrm{c}}$ Major comorbidity included cardiovascular disease, COPD, renal failure, diabetes and malignancy

Table 2 Association between severity of PTSD symptoms (three categories) and other traumatic experiences following peritonitis

\begin{tabular}{lcccc}
\hline \multicolumn{2}{c}{ PTSD symptoms $(n=105)$} & & $\begin{array}{c}\text { Univariate } \\
\text { ordinal } \\
\text { regression } \\
p \text {-value }\end{array}$ \\
& $\begin{array}{l}\text { None to mild } \\
(n=64)^{\mathrm{a}}\end{array}$ & $\begin{array}{l}\text { Moderate } \\
(n=30)^{\mathrm{a}}\end{array}$ & $\begin{array}{l}\text { High } \\
(n=11)\end{array}$ & \\
\hline Traumatic memories of ICU or hospital stay & & & \\
$\quad$ Nightmares & $39 \%$ & $61 \%$ & $82 \%$ & $<0.002$ \\
Fear and panic & $24 \%$ & $61 \%$ & $100 \%$ & 0.002 \\
Pain & $67 \%$ & $70 \%$ & $82 \%$ & $<0.001$ \\
Difficulty breathing & $33 \%$ & $76 \%$ & $100 \%$ & $<0.001$ \\
Traumatic memories & $41 \%$ & $50 \%$ & $9 \%$ & \\
$\quad$ None $(0)$ & $7 \%$ & $47 \%$ & $47 \%$ & \\
Moderate (1-4) & $0 \%$ & $18 \%$ & $82 \%$ & \\
Severe $(>4)$ & & & & \\
\hline
\end{tabular}

a Two patients not included in final analysis due to missing data on traumatic memories during ICU or hospital stay 
Fig. 2 Nomogram for prediction of severity of PTSD symptoms in patients with secondary peritonitis. Graded outcome categories are: none to mild (negative on both instruments), moderate (positive on one instrument), and severe (positive on both instruments)

\section{Section 1:}

Age:
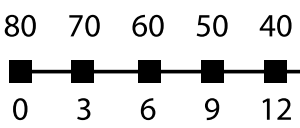

Gender:

\section{F M}

ICU stay:

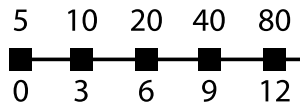

Major morbidity:

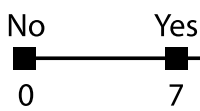

Hospital and

ICU memories:

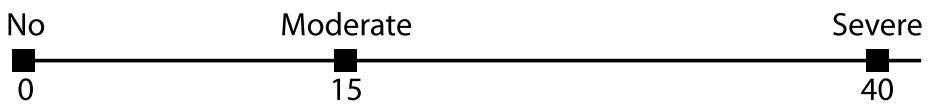

Other trauma:

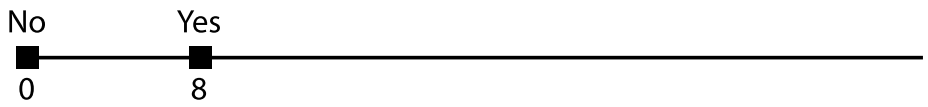

\section{Section 2:}

Total points

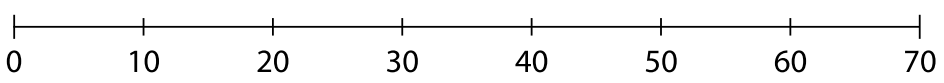

PTSD symptomology distribution
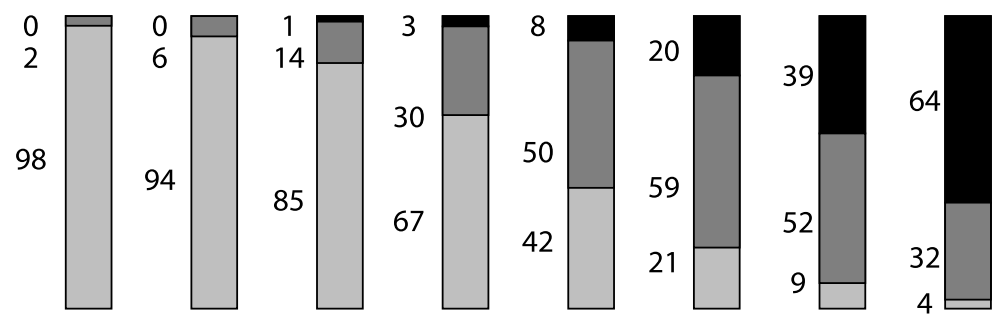

Low PTSD symptoms

Moderate PTSD symptoms

High PTSD symptoms

\section{Instructions:}

From section 1 of the nomogram, locate the age of the patient on the axis. Determine how many points the patient receives. Repeat this for each factor in section 1 . Sum the points for all predictors.

From section 2, locate this sum score on the total points axis. Draw a line straight down to the bar graphs. These bars indicate the estimated probability of that patient having 'no to mild' PTSD symptoms (negative on both instruments),'moderate' PTSD symptoms (positive on one instrument) and 'high' PTSD symptoms (positive on both instruments).

Predictive factors

Results from the univariate analysis are presented in Table 1 and Table 2, and descriptive details can be found in the ESM.
The final multivariate model included age, gender, length of ICU stay, disease-related morbidity during the 6-month follow-up, traumatic memories of the ICU or hospital stay and other traumatic factors within the previous 3 years (Table 3 ). 
Table 3 Association between severity of PTSD symptoms and patient, disease operative and postoperative characteristics and other traumatic experiences following peritonitis in a multivariate analysis
Fig. 3 Distribution of total points from nomogram (risk score) for the prediction of the severity of PTSD symptoms with use of the risk factors taken from the multivariate ordinal model. PTSD categories are graded according to severity: none to mild (negative on both instruments), moderate (positive on one instrument), severe (positive on both instruments)

\begin{tabular}{|c|c|c|c|c|}
\hline & \multicolumn{3}{|c|}{ Final model $(n=105)^{\mathrm{a}}$} & \multirow[b]{2}{*}{$p$-value } \\
\hline & OR & $\begin{array}{l}95 \% \mathrm{CI} \\
\text { Lower }\end{array}$ & Upper & \\
\hline Ten years increase in age & 0.74 & 0.53 & 1.04 & 0.084 \\
\hline Female & 0.9 & 0.94 & 2.3 & 0.822 \\
\hline Length of ICU stay (log2 transformed) & 1.4 & 1.1 & 1.7 & $<0.003$ \\
\hline $\begin{array}{l}\text { Major disease-related morbidity during 6-month } \\
\text { follow-up (including index hospital admittance) }\end{array}$ & 2.1 & 0.61 & 7.11 & 0.238 \\
\hline \multicolumn{5}{|l|}{ Traumatic memories of ICU or hospital stay } \\
\hline Moderate (1-4) & 4.9 & 0.95 & 24.9 & 0.058 \\
\hline Severe $(>4)$ & 55.5 & 9.4 & 328.0 & $<0.001$ \\
\hline Other trauma within previous 3 years & 2.4 & 0.94 & 6.3 & 0.085 \\
\hline
\end{tabular}

${ }^{a}$ This multivariate ordinal analysis included a test for parallel lines $(p=0.694)$

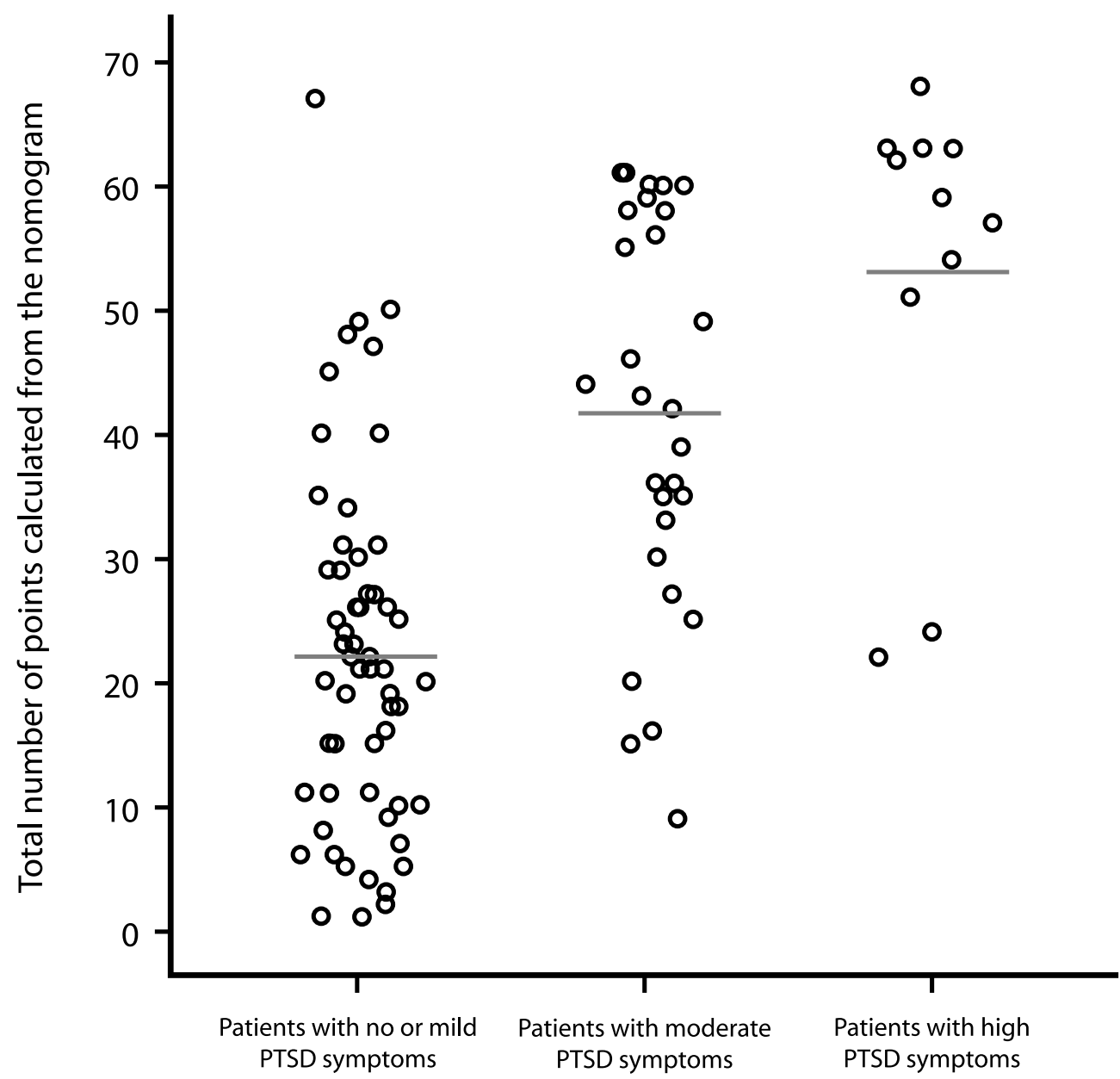

In our final model, increasing age was associated with a lower likelihood of PTSD symptomatology $(\mathrm{OR}=0.74$ per 10 years increase in age, $p=0.084)$. Gender was not predictive of PTSD symptoms $(\mathrm{OR}=0.90, p=0.82)$. Disease-related morbidity at the 6-month follow-up $(\mathrm{OR}=2.1, p=0.24)$ was no longer independently predictive of PTSD symptoms. Memories of the ICU/hospital stay (patients that reported some memories: $\mathrm{OR}=4.9$, $p<0.057$; patients that reported many memories:
$\mathrm{OR}=55.5, p<0.001)$ were the most prominent independent risk factor for increased PTSD symptomatology. Length of ICU stay was also significantly predictive in the development of PTSD symptomatology in the multivariate model $(\mathrm{OR}=1.4, p=0.004)$. The relative strengths of these relationships are visualized in the nomogram (Fig. 2). In this nomogram, one can calculate for the individual patient given his/her risk profile the probability that he/she will score either no to mild, moderate or 
high PTSD symptoms according to the PTSS-10 and IES-R.

The proportional odds assumption was not violated as indicated by a $p$-value of 0.694 for the test of parallel lines. Calibration of the model (closeness between predicted and observed probabilities) was good, with a $p$-value of 0.987 for the goodness-of-fit test for ordinal models. A graphical impression of the model's discriminative ability is shown in Fig. 3. This figure shows that the mean risk score is significantly different between all three PTSD symptom severity categories $(p<0.001)$, although there is some substantial overlap in the risk scores between patients from different categories of PTSD symptom severity.

\section{Discussion}

The proportion of patients with 'high-scoring' PTSD symptomatology 12 months after peritonitis was $10 \%$, and the number of 'medium-scoring' patients $(28 \%)$ was in line with earlier studies measuring PTSD symptoms in critically ill patients who had been admitted to ICU [9-13, 15, 42]. The prevalence of PTSD recorded in the general population varies between $0.9 \%$ and $2.9 \%$ (the ESEMeD study) [7, 43, 44].

From our study, the following observations can be made. Firstly, the development of PTSD symptoms is not directly related to the severity of the disease at presentation. The APS score at baseline was not predictive for the development of PTSD symptoms. The APS measures the severity of disease score solely on the weight of the acute clinical features and does not incorporate age and comorbidity [36].

The development of PTSD symptoms was, however, predominantly related to a more complicated course of secondary peritonitis. Longer ICU and hospital stays and major disease-related morbidity during the 12-month follow-up were associated with more PTSD symptoms. In concordance with earlier studies [15, 34], the strongest predictor of having PTSD symptoms following abdominal sepsis was having traumatic memories and experiences during their initial hospital or ICU stay. These results suggest that the presence of traumatic memories is one of the most relevant aspects for the development of PTSD-related symptoms. Earlier studies also found that subjective interpretation of the intensive care experience emerged as a consistent predictor of adverse emotional outcome in both the short and the long term $[13,34]$.

Age plays a critical role in the development of PTSD symptoms. Younger patients are much more likely to develop and report such symptoms. This finding confirms the results of an earlier, retrospective study of a different cohort of patients 4-10 years after hospital admission for severe peritonitis [15]. These findings suggest that older patients are more able to adapt to the limitations that are associated with experiencing such a major disease, most likely because they have already experienced a co-morbid illness and health-related problems. In contrast to some other studies, gender did not play a role in the development of PTSD symptoms [34].

Patients with abdominal sepsis suffering from ARDS did not report more PTSD symptomatology than those without ARDS. In earlier ICU studies, ARDS patients reported considerable PTSD symptoms [12, 45]. In our cohort of abdominal sepsis patients we found different predictive factors for PTSD than those found in the ARDS patients $[10,12,15]$. Secondary peritonitis in itself may have been severe enough, with ICU admission and extended mechanical ventilation days, to cause PTSD symptoms; therefore, the added risk by ARDS may be moot. Lack of power may also be a factor, because the proportion of patients developing ARDS in this study was modest.

We did not find an association between hydrocortisone administration during ICU stay and PTSD symptoms within this peritonitis cohort, as has been demonstrated for other critically ill patient groups [13, 37, 46, 47]. Hydrocortisone did not protect against developing PTSD symptoms, whereas other studies have found that administration of hydrocortisone during ICU can lead to a reduction in PTSD symptoms after discharge. In this study corticosteroid use during only the first 14 days of ICU was included in our analyses. The effect of prolonged use of hydrocortisone or late-stage use during conditional adrenal insufficiency cannot be excluded.

Unfortunately, due to the acute and life-threatening nature of secondary peritonitis, it was not possible to collect baseline information on PTSD or data on earlier psychological disorders. However, as recommended in a recent review by Griffiths and colleagues [48], to account for possible earlier traumas we considered information pertaining to comorbid diseases. Furthermore, we collected data on other, non-disease-related traumatic events that had occurred within the previous 3 years. These non-diseaserelated events were indeed associated with having more PTSD symptoms, and altered the initial ORs of the other factors to the extent that we considered it a moderate confounder.

Timing plays an important role in collecting data on PTSD symptoms in critically ill and ICU patients [48]. We set the period for the recording of PTSD symptoms at 12 months for a very specific reason; in this severely ill patient group, we did not want to record patient recovery. Past studies have shown that critically ill patients develop PTSD symptoms only after their physical recovery period has passed, hence with a delayed onset [9].

Although these self-report questionnaires are frequently used, the diagnostic value of such instruments in relation to a DSM-IV diagnosis obtained by a structured interview is still being researched and discussed [49]. Some studies have reviewed the diagnostic value of the questionnaires, but in general these studies were 
methodologically limited $[11,29,50]$. In this study we did not include a structured clinical interview for establishing a definite DSM-IV criteria diagnosis of PTSD, although this is highly recommended in clinical psychology. However, we feel that the use of questionnaires is more feasible in the ICU [48], and patients who report many symptoms on these self-report questionnaires [51] can subsequently be referred to an appropriate mental healthcare provider [50].

In this study we have tried to learn from two questionnaires, one commonly used and validated in particular for critically ill patients, together with one of the most frequently used screening instruments for PTSD, the IES-R. The prevalence of PTSD symptomatology in the present study was based on whether or not a patient scored above the cut-offs of the IES-R and the PTSS-10. We employed the two questionnaires as complementary for the detection of PTSD symptoms and not to compare results deduced from both questionnaires separately [49]. Combining the results of both questionnaires in our analysis was anticipated to lead to a more robust assessment of the factors associated with more PTSD symptoms. Although these two instruments aim to measure the presence of PTSD symptoms, their concordance in classification of patients was not perfect, with 30 patients (28\%) being positive on one questionnaire but not on the other. This demonstrates the difficulty in measuring PTSD symptoms by questionnaire, but also means that both questionnaires are informative in their own right. Combining the two instruments may therefore lead to a more robust classification of patients based on their level of PTSD symptoms and may be a more useful tool in screening patients following ICU stay, while potentially reducing biases due to instrument variation [52].

We assessed traumatic experiences during ICU/hospital stay based on the patients' recollections (after 1 year). The patients' perceived traumatic experience may well have contributed to the development of PTSD symptoms, but it is also possible that having PTSD symptoms influenced their perceptions. Future studies should aim to prospectively quantify traumatic experiences during or shortly after ICU stay to draw more causal conclusions, even though this might be difficult in patients with such a lengthy recovery period $[9,48,53,54]$.

In the clinical setting, there is a continuing debate on whether to intervene in the more acute peritraumatic psychological processes or in a later phase, when symptoms or prodromes of PTSD are observed. By improving our understanding of which factors play an important role in the development of PTSD, we can better prevent PTSD symptoms in high-risk patients and decide when best to intervene. The aim of our predictive model is for it to be used by treating physicians, following the acute episode and phase of secondary peritonitis in which survival and physical recovery are the main concerns, to recognize high-risk PTSD patients. This relatively simple model can aid the surgeon, for instance, during the first outpatient visit in determining which patients are at higher risk for the development of PTSD symptoms. However, before this nomogram can be used to actually predict PTSD symptomatology in clinical practice, it must be externally validated in another cohort of patients with secondary peritonitis.

In conclusion, $10 \%$ of peritonitis patients report 'high' PTSD symptomatology and another 28\% 'moderate' PTSD symptoms. Factors that were related to more PTSD symptoms included younger age, traumatic memories of the period of hospitalization and length of ICU stay. Knowledge of these predictive factors is required to increase awareness, and to develop tailored early treatment options for these high-risk patients our nomogram may assist in identifying patients with PTSD symptoms.

Open Access. This article is distributed under the terms of the Creative Commons Attribution Noncommercial License which permits any noncommercial use, distribution, and reproduction in any medium, provided the original author(s) and source are credited.

\section{Appendix: RELAP trial clinical centers and investigators of the Dutch Peritonitis Study Group}

All investigators are from departments of surgery unless specified as clinical epidemiology and biostatistics (E), intensive care (I) or medical psychology (MP).

O. van Ruler, K. R. Boer (E), J. B. Reitsma (E), C. W. Mahler, E. A. Reuland, J. W. O. van Till, B. C. Opmeer (E), P. M. M. Bossuyt (E), M. J. Schultz (I), M. A. Sprangers (MP), H. Obertop, D. J. Gouma, C. A. J. M. de Borgie (E), M. A. Boermeester: Academic Medical Center, Amsterdam; E. P. Steller, P. Tanis, H. Hart (I): Sint Lucas Andreas Hospital, Amsterdam; M. F. Gerhards, M. Guijt, H. M. Oudemans (I): Onze Lieve Vrouwe Gasthuis, Amsterdam; K. Bosscha, E. Ritchie, M. Vermeer: Bosch Medical Centre, Den Bosch; P. W. de Graaf, B. van Etten, C. Haazer, E. Salm (I): Reinier de Graaf Hospital, Delft; B. Lamme, E. J. Hesselink, H. Rommes (I): Gelre Hospitals, Lukas Hospital, Apeldoorn; R. J. Oostenbroek, L. te Velde, G. Govaert, H. H. Ponssen (I): Albert Schweitzer Hospital, Dordrecht; H. G. Gooszen, M. K. Dinkelman, L. P. H. Leenen (I): University Medical Centre Utrecht; E. G. J. M. Pierik, K. W. W. Lansink, J. Bakker (I): Isala Clinics, Zwolle.

Key staff and steering committee at coordinating center of RELAP trial: O. van Ruler (investigator), E. A. Reuland (data management), C. W. Mahler (investigator), J. B. Reitsma (epidemiologist), C. A. J. M. de Borgie (epidemiologist), K. R. Boer (quality of life investigator), B. C. Opmeer (economist), M. A. Boermeester (principal investigator, project supervisor) from the Department of Surgery, Academic Medical Center Amsterdam, The Netherlands. 


\section{References}

1. Gersons BP, Carlier IV (1992) Post-traumatic stress disorder: the history of a recent concept. Br J Psychiatry 161:742-748

2. Horowitz MJ (1993) Response syndromes. A Review of posttraumatic stress and adjustment disorders. In: Wilson JP, Raphael B (eds) International handbook of traumatic stress syndromes. Plenum Press, New York, pp 49-60

3. American Psychiatric Association (1994) Diagnostic and statistical manual of mental disorders. Posttraumatic stress disorder syndrome, 4th edn. Harcourt Assessment, Washington DC

4. Deja M, Denke C, Weber-Carstens S, Schröder J, Pille CE, Hokema F, Falke KJ, Kaisers U (2006) Social support during intensive care unit stay might improve mental impairment and consequently health-related quality of life in survivors of severe acute respiratory distress syndrome. Crit Care 10:R147

5. Breslau N, Davis GC, Peterson EL, Schultz LR (2000) A second look at comorbidity in victims of trauma: the posttraumatic stress disordermajor depression connection. Biol Psychiatry 48:902-909

6. Perkonigg A, Kessler RC, Storz S, Wittchen HU (2000) Traumatic events and post-traumatic stress disorder in the community: prevalence, risk factors and comorbidity. Acta Psychiatr Scand 101:46-59

7. Frans O, Rimmo PA, Aberg L, Fredrikson M (2005) Trauma exposure and post-traumatic stress disorder in the general population. Acta Psychiatr Scand 111:291-299

8. Davidson JR, Hughes D, Blazer DG, George LK (1991) Post-traumatic stress disorder in the community: an epidemiological study. Psychol Med 21:713-721

9. Cuthbertson BH, Hull A, Strachan M, Scott J (2004) Post-traumatic stress disorder after critical illness requiring general intensive care. Intensive Care Med 30:450-455

10. Kapfhammer HP, Rothenhausler HB, Krauseneck T, Stoll C, Schelling G (2004) Posttraumatic stress disorder and health-related quality of life in long-term survivors of acute respiratory distress syndrome. Am J Psychiatry 161:45-52
11. Nickel M, Leiberich P, Nickel C, Tritt K, Mitterlehner F, Rother W, Loew T (2004) The occurrence of posttraumatic stress disorder in patients following intensive care treatment: a cross-sectional study in a random sample. J Intensive Care Med 19:285-290

12. Schelling G, Stoll C, Haller M, Briegel J, Manert W, Hummel T, Lenhart A, Heyduck M, Polasek J, Meier M, Preuss U, Bullinger M, Schuffel W, Peter K (1998) Healthrelated quality of life and posttraumatic stress disorder in survivors of the acute respiratory distress syndrome. Crit Care Med 26:651-659

13. Schelling G, Kilger E, Roozendaal B, de Quervain DJ, Briegel J, Dagge A, Rothenhausler HB, Krauseneck T, Nollert G, Kapfhammer HP (2004) Stress doses of hydrocortisone, traumatic memories, and symptoms of posttraumatic stress disorder in patients after cardiac surgery: a randomized study. Biol Psychiatry 55:627-633

14. Richter JC, Waydhas C, Pajonk FG (2006) Incidence of posttraumatic stress disorder after prolonged surgical intensive care unit treatment. Psychosomatics 47:223-230

15. Boer KR, Mahler CW, Unlu C, Lamme B, Vroom MB, Sprangers MA, Gouma DJ, Reitsma JB, De Borgie CA, Boermeester MA (2007) Long-term prevalence of posttraumatic stress disorder symptoms in patients after secondary peritonitis. Crit Care 11:R30

16. Quartin AA, Schein RM, Kett DH, Peduzzi PN (1997) Magnitude and duration of the effect of sepsis on survival. Department of Veterans Affairs Systemic Sepsis Cooperative Studies Group. JAMA 277:1058-1063

17. Brun-Buisson C, Doyon F, Carlet J, Dellamonica P, Gouin F, Lepoutre A, Mercier JC, Offenstadt G, Regnier B (1995) Incidence, risk factors, and outcome of severe sepsis and septic shock in adults. A multicenter prospective study in intensive care units. French ICU Group for Severe Sepsis. JAMA 274:968-974

18. Pittet D, Rangel-Frausto S, Li N, Tarara D, Costigan M, Rempe L, Jebson P, Wenzel RP (1995) Systemic inflammatory response syndrome, sepsis, severe sepsis and septic shock: incidence, morbidities and outcomes in surgical ICU patients. Intensive Care Med 21:302-309
19. Alberti C, Brun-Buisson C, Goodman SV, Guidici D, Granton J, Moreno R, Smithies M, Thomas O, Artigas A, Le Gall JR (2003) Influence of systemic inflammatory response syndrome and sepsis on outcome of critically ill infected patients. Am J Respir Crit Care Med 168:77-84

20. Granja C, Dias C, Costa-Pereira A, Sarmento A (2004) Quality of life of survivors from severe sepsis and septic shock may be similar to that of others who survive critical illness. Crit Care 8:R91-R98

21. Lamme B, Boermeester MA, Belt EJ, van Till JW, Gouma DJ, Obertop H (2004) Mortality and morbidity of planned relaparotomy versus relaparotomy on demand for secondary peritonitis. Br J Surg 91:1046-1054

22. Lamme B, Boermeester MA, Reitsma JB, Mahler CW, Obertop H, Gouma DJ (2002) Meta-analysis of relaparotomy for secondary peritonitis. Br J Surg 89:1516-1524

23. van Ruler O, Mahler CW, Boer KR, Reuland EA, Gooszen HG, Opmeer B, de Graaf P, Lamme B, Gerhards M, Stellar E, van Till JW, De Borgie CA, Gouma DJ, Reitsma JB, Boermeester MA (2007) Comparison of on-demand vs planned relaparotomy strategy in patients with severe peritonitis: a randomized trial. JAMA 298:865-872

24. Eid J, Thayer JF, Johnsen BH (1999) Measuring post-traumatic stress: a psychometric evaluation of symptom- and coping questionnaires based on a Norwegian sample. Scand J Psychol 40:101-108

25. Ersland S, Weisaeth L, Sund A (1989) The stress upon rescuers involved in an oil rig disaster. "Alexander L. Kielland" 1980. Acta Psychiatr Scand Suppl 355:38-49

26. Weisaeth L (1989) Torture of a Norwegian ship's crew. The torture, stress reactions and psychiatric after-effects. Acta Psychiatr Scand Suppl 355:63-72

27. Elhai JD, Gray MJ, Kashdan TB, Franklin CL (2005) Which instruments are most commonly used to assess traumatic event exposure and posttraumatic effects? A survey of traumatic stress professionals. J Trauma Stress 18:541-545

28. Creamer M, Bell R, Failla S (2003) Psychometric properties of the Impact of Event Scale-Revised. Behav Res Ther 41:1489-1496 
29. Stoll C, Kapfhammer HP, Rothenhausler HB, Haller M, Briegel J, Schmidt M, Krauseneck T, Durst K, Schelling G (1999) Sensitivity and specificity of a screening test to document traumatic experiences and to diagnose post-traumatic stress disorder in ARDS patients after intensive care treatment. Intensive Care Med 25:697-704

30. Baumert J, Simon H, Gundel H, Schmitt C, Ladwig KH (2004) The Impact of Event Scale-Revised: evaluation of the subscales and correlations to psychophysiological startle response patterns in survivors of a life-threatening cardiac event. An analysis of 129 patients with an implanted cardioverter defibrillator. J Affect Disord 82:29-41

31. Harrell FE Jr., Lee KL, Mark DB (1996) Multivariable prognostic models: issues in developing models, evaluating assumptions and adequacy, and measuring and reducing errors. Stat Med 15:361-387

32. McLauchlan GJ, Anderson ID, Grant IS, Fearon KC (1995) Outcome of patients with abdominal sepsis treated in an intensive care unit. Br J Surg 82:524-529

33. Haraldsen P, Andersson R (2003) Quality of life, morbidity, and mortality after surgical intensive care: a follow-up study of patients treated for abdominal sepsis in the surgical intensive care unit. Eur J Surg Suppl 588:23-27

34. Rattray JE, Johnston M, Wildsmith JA (2005) Predictors of emotional outcomes of intensive care. Anaesthesia 60:1085-1092

35. Breslau N, Davis GC, Andreski P, Peterson EL, Schultz LR (1997) Sex differences in posttraumatic stress disorder. Arch Gen Psychiatry 54:1044-1048

36. Iezzoni LI, Ash AS, Coffman GA, Moskowitz MA (1992) Predicting in-hospital mortality. A comparison of severity measurement approaches. Med Care 30:347-359

37. Schelling G, Roozendaal B, de Quervain DJ (2004) Can posttraumatic stress disorder be prevented with glucocorticoids? Ann N Y Acad Sci 1032:158-166

38. Wolfe J, Kimerling R (1997) Gender issues in the assessment of posttraumatic stress disorder. In: Wilson J, Keane TM (eds) Assessing psychological trauma and PTSD. A handbook for practitioners. Guilford, New York, pp 192-238
39. Brown L, Cai TT, DasGupta A (2001) Interval estimation for binomial proportion. Stat Sci 16:101-133

40. Norris CM, Ghali WA, Saunders LD, Brant R, Galbraith D, Faris P, Knudtson ML (2006) Ordinal regression model and the linear regression model were superior to the logistic regression models. J Clin Epidemiol 59:448-456

41. Lipsitz SR, Fitzmaurice GM, Molenberghs G (1996) Goodness-of-fit tests for ordinal response regression models. Appl Statist 45:175-190

42. Capuzzo M, Valpondi V, Cingolani E, Gianstefani G, De Luca S, Grassi L, Alvisi R (2005) Posttraumatic stress disorder-related symptoms after intensive care. Minerva Anestesiol 71:167-179

43. Alonso J, Angermeyer MC, Bernert S, Bruffaerts R, Brugha TS, Bryson H, de Girolamo G, Graaf R, Demyttenaere K, Gasquet I, Haro JM, Katz SJ, Kessler RC, Kovess V, Lepine JP, Ormel J, Polidori G, Russo LJ, Vilagut G, Almansa J, ArbabzadehBouchez S, Autonell J, Bernal M, Buist-Bouwman MA, Codony $\mathrm{M}$ et al. (2004) 12-Month comorbidity patterns and associated factors in Europe: results from the European Study of the Epidemiology of Mental Disorders (ESEMeD) project. Acta Psychiatr Scand Suppl 420:28-37

44. Alonso J, Angermeyer MC, Bernert S, Bruffaerts R, Brugha TS, Bryson $\mathrm{H}$, de Girolamo G, Graaf R, Demyttenaere K, Gasquet I, Haro JM, Katz SJ, Kessler RC, Kovess V, Lepine JP, Ormel J, Polidori G, Russo LJ, Vilagut G, Almansa J, ArbabzadehBouchez S, Autonell J, Bernal M, Buist-Bouwman MA, Codony $\mathrm{M}$ et al (2004) Disability and quality of life impact of mental disorders in Europe: results from the European Study of the Epidemiology of Mental Disorders (ESEMeD) project. Acta Psychiatr Scand Suppl 420:38-46

45. Schelling G, Stoll C, Vogelmeier C, Hummel T, Behr J, Kapfhammer HP, Rothenhausler HB, Haller M, Durst K, Krauseneck T, Briegel J (2000) Pulmonary function and healthrelated quality of life in a sample of long-term survivors of the acute respiratory distress syndrome. Intensive Care Med 26:1304-1311
46. Schelling G, Stoll C, Kapfhammer HP, Rothenhausler HB, Krauseneck T, Durst K, Haller M, Briegel J (1999) The effect of stress doses of hydrocortisone during septic shock on posttraumatic stress disorder and healthrelated quality of life in survivors. Crit Care Med 27:2678-2683

47. Schelling G, Briegel J, Roozendaal B, Stoll C, Rothenhausler HB, Kapfhammer HP (2001) The effect of stress doses of hydrocortisone during septic shock on posttraumatic stress disorder in survivors. Biol Psychiatry 50:978-985

48. Griffiths J, Fortune G, Barber V, Young JD (2007) The prevalence of post traumatic stress disorder in survivors of ICU treatment: a systematic review. Intensive Care Med 33:1506-1518

49. Weinert C, Meller W (2007) Medical post-traumatic stress disorder: catching up with the cutting edge in stress research. Crit Care 11:118

50. Wohlfarth TD, van den BW, Winkel FW, ter Smitten M (2003) Screening for posttraumatic stress disorder: an evaluation of two selfreport scales among crime victims. Psychol Assess 15:101-109

51. Thatcher DL, Krikorian R (2005) Exploratory factor analysis of two measures of posttraumatic stress disorder (PTSD) symptoms in a non-clinical sample of college students. J Anxiety Disord 19:904-914

52. Whiting P, Rutjes AW, Reitsma JB, Glas AS, Bossuyt PM, Kleijnen J (2004) Sources of variation and bias in studies of diagnostic accuracy: a systematic review. Ann Intern Med 140:189-202

53. Jones C, Backman C, Capuzzo M, Flaatten H, Rylander C, Griffiths RD (2007) Precipitants of post-traumatic stress disorder following intensive care: a hypothesis generating study of diversity in care. Intensive Care Med 33:978-985

54. Samuelson KA, Lundberg D, Fridlund B (2007) Stressful memories and psychological distress in adult mechanically ventilated intensive care patients-a 2-month follow-up study. Acta Anaesthesiol Scand 51:671-678 